\title{
Analisis Aspek Kualitas Skema Basis Data (Studi Kasus Pada Aplikasi LaundryPOS)
}

\author{
Database Schema Quality Aspect Analysis \\ (Case Study in LaundryPOS Application)
}

\author{
Muhammad Resa Arif Yudianto ${ }^{1}$, Arham Rahim ${ }^{2}$,Ema Utami ${ }^{3}$ \\ 1,2,3 Magister Teknik Informatika, Universitas Amikom Yogyakarta \\ E-mail: ${ }^{1}$ muhammad.yudianto@students.amikom.ac.id, ${ }^{2}$ arham.rahim@students.amikom.ac.id, \\ 3emma@nrar.net
}

\begin{abstract}
Abstrak
Semua sektor bisnis pasti membutuhkan peran basis data di dalam sistem informasi. Basis data berperan dalam pengelolaan data untuk membantu pengambilan keputusan. Basis data yang baik adalah basis data yang mampu menjamin keamanan maupun integritas data. Agar terwujudnya sebuah skema basis data yang baik, perlu dilakukan sebuah cara agar menjaga data yang ada dari kesalahan dalam pengolahan data yang dapat berakibat fatal. Salah satu caranya adalah dengan menganalisa aspekaspek skema database yang ada pada aplikasi LaundryPOS seperti kriteria kebenaran (correctness), konsistensi (consistency) dan relevansi (relevance), sehingga dapat menghasilkan perancangan database yang dapat digunakan secara optimal. Hasil penelitian ini diharapkan dapat memberikan rekomendasi langkah yang mungkin dilakukan oleh pengelola/penanggung jawab database aplikasi LaundryPOS.
\end{abstract}

Kata Kunci-Kualitas skema, konsistensi, relevansi

\begin{abstract}
All business sectors certainly need the role of databases in information systems. Databases play a role in data management to help decision making. A good database can able to guarantee data security and integrity. To make a good database schema, it is necessary to do a way to keep the existing data from errors in data processing that can be fatal. One way is to analyze aspects of the database schema in LaundryPOS application such as the correctness criteria, consistency and relevance, so as to produce a database design that can be used optimally. The results of this study are expected to provide recommendations for steps that might be taken by the manager / person in charge of the LaundryPOS database application.
\end{abstract}

Keywords—Schema quality, consistency, relevancy

\section{Pendahuluan}

Basis data merupakan bagian penting dari sebuah sistem yaitu sebagai sumber informasi serta sebagai sarana mencapai sistem informasi yang efektif dan efisien [1]. Menurut Fabbri dan Schwab definisi database atau basis data adalah suatu sistem berkas terpadu yang dirancang khusus untuk dapat meminimalkan pengulangan atau redundancy data [2]. Basis data biasanya di simpan di dalam server dan sebagai pendukung suatu program aplikasi yang sewaktu-waktu dapat diakses sesuai kepentingan [3]. Pemodelan data dan desain basis data telah mengalami evolusi signifikan dalam beberapa tahun terakhir sejak dominasi aplikasi bisnis oleh model data relasional dan sistem basis data relasional [4]. Tanpa mengabaikan sumber daya informasi yang lainnya, aspek rekayasa Sistem Informasi, khususnya desain struktur tabel database sangat mempengaruhi keberhasilan implementasi Sistem Informasi. Desain struktur tabel database yang fleksibel akan meningkatkan kualitas Sistem Informasi, sebaliknya desain struktur tabel database yang tidak fleksibel berpotensi menimbulkan masalah dan kegagalan implementasi. Struktur tabel database seharusnya dirancang sedemikian rupa sehingga fleksibel terhadap perubahan kebutuhan informasi dan data untuk memenuhi kebutuhan para penggunanya [5].

Banyak metode yang dikembangkan dan digunakan dalam perancangan sistem basis data salah satunya adalah Database Life Cycle [6]. Selain itu, banyak penelitian yang menjelaskan tentang proses 
perbaikan database untuk menjaga kualitas data [7]. Salah satu perbaikan data adalah menggunakan meta model, metode ini telah berhasil mendefinisikan dan mengukur aspek - aspek kualitas suatu schema database dan mengusulkan sebuah proses untuk melakukan tinjauan dan pengukuran aspek kualitas suatu database. Aspek - aspek yang relevan untuk pengukuran aspek kualitas suatu database yang dimaksud meliputi 9 (sembilan) kriteria, yaitu kebenaran (correctness), konsistensi (consistency), relevansi (relevance), jangkauan (scope), tingkat detail (level of detail), kelengkapan (completeness), minimalitas (minimality), kemampuan untuk diintegrasikan (ability of integration), serta kemampuan untuk dibaca (readability) [8].

Penelitian ini akan melakukan sebuah analisis atau pengujian yang berfokus pada aspek kebenaran (correctness), konsistensi (consistency) dan relevansi (relevance) pada schema database yang digunakan pada aplikasi LaundryPOS. Penelitian ini bertujuan untuk mengetahui kualitas database yang digunakan pada aplikasi LaundryPOS. Hasil dari penelitian ini diharapkan dapat memberi manfaat berupa rekomendasi alternatif - alternatif solusi yang mungkin dilakukan oleh pengelola/pemilik database aplikasi LaundryPOS.

\section{Metode Penelitian}

\subsection{Tahapan Review}

Dalam bagian tahapan review ini, peneliti akan menjelaskan tentang alur penelitian yang akan dijalankan. Tahapan tahapan ini terdiri dari studi literatur dan identifikasi masalah, pengumpulan data, analisa tabel beserta relasi dan constraint, dan penarikan kesimpulan serta pemberian rekomendasi. Alur penelitian lebih lengkap dapat dilihat pada gambar 1 [11].

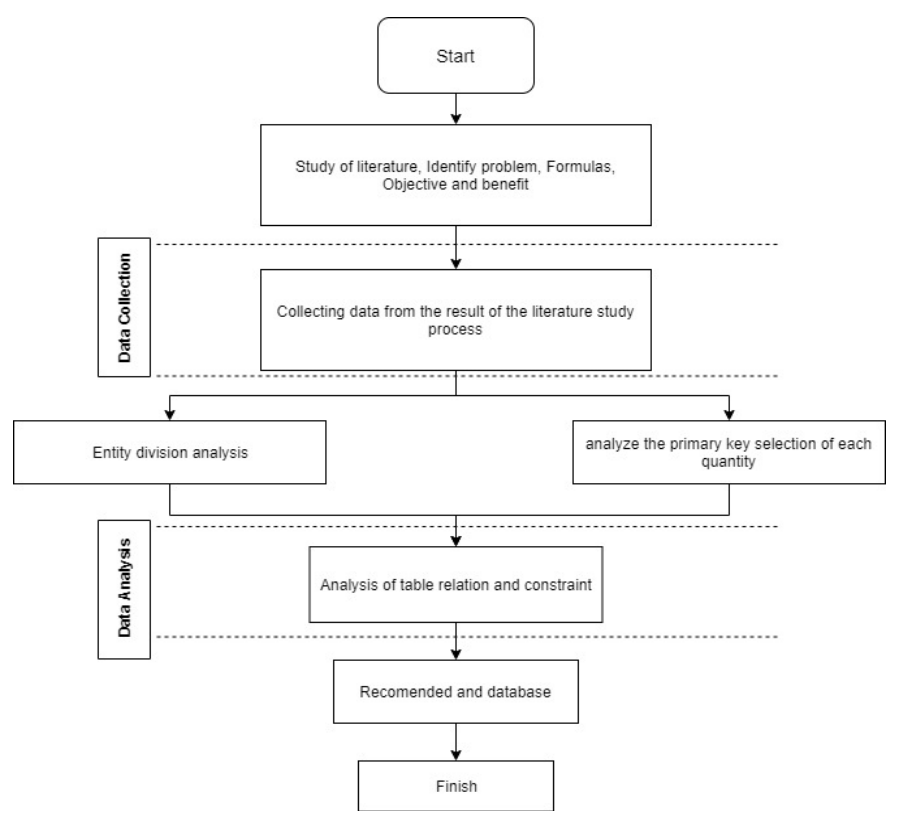

Gambar 1. Alur Penelitian

2.2. Tinjauan Literatur

Penelitian ini mengacu pada penelitian serupa yang ditulis oleh Herden [8]. Penelitian yang ditulis oleh Herden membahas tentang penggunaan meta model pada pengujian kualitas skema. Metode ini telah berhasil mendefinisikan dan mengukur aspek - aspek kualitas suatu skema database dan mengusulkan sebuah proses untuk melakukan tinjauan dan pengukuran aspek kualitas suatu database.

\subsection{Pengumpulan data}

Proses pengumpulan data untuk bahan penelitian ini dilakukan dengan mengumpulkan data yang diperlukan untuk bahan penelitian dan berbagai data dari data aplikasi LaundryPOS. 


\subsection{Analisis data}

Proses analisis data dilakukan dengan menganalisis tabel relasi yang ada dengan melakukan analisis terhadap aspek kualitas data. Setelah itu, peneliti akan memetakan relasi tabel dan kendala, yang hasilnya adalah rekomendasi database.

\section{Hasil dan Pembahasan}

Pada penelitian ini dilakukan analisis kualitas basis data yang digunakan aplikasi LaundryPOS terkait 3 aspek kualitas skema basis data yang akan menjadi rujukan dan saran untuk merancang basis data baru. Ketiga aspek tersebut adalah aspek kebenaran, konsistensi, dan relevansi [9]. Jumlah tabel dalam basis data aplikasi LaundryPOS ini terdapat 11 tabel yang antar tabelnya terdapat relasi kolom akan tetapi tidak adanya constraint relasi antar tabelnya, sehingga perlunya dilakukan analisis melalui ke 3 aspek di atas. Tampilan di gambar 2 adalah skema basis data lama dari aplikasi LaundryPOS.
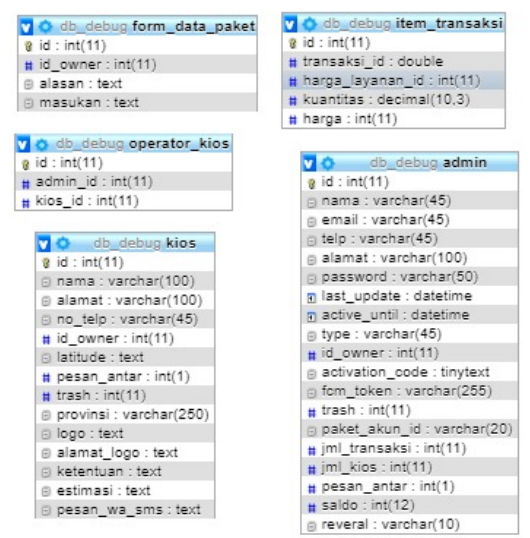
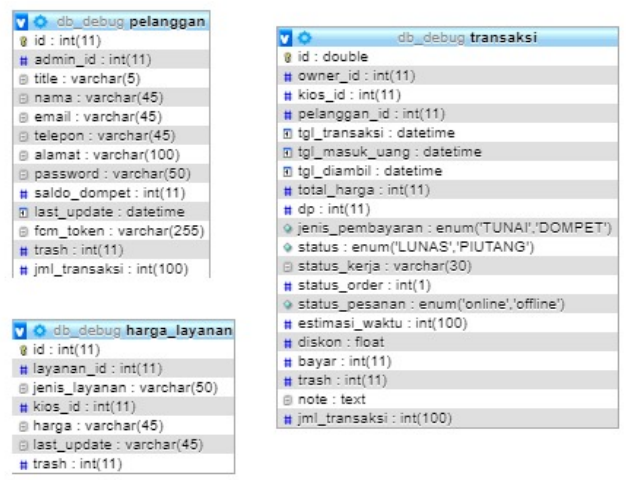

Gambar 2. Skema basis data lama

Dalam penelitian ini dibuat beberapa skenario pengecekan kualitas skema basis data berdasarkan aspek kebenaran, konsistensi dan relevansi dengan melakukan analisis melalui perintah-perintah query masingmasing satu contoh permasalahan untuk setiap aspeknya :

\subsection{Aspek Kebenaran}

Dalam aspek kebenaran ini akan dianalisis tingkat kebenaran data yang dimasukkan apakah skema basis data lama seperti pada gambar 2 sudah menjamin kebenaran data yang dimasukkan dan akan menolak proses simpan jika data yang dimasukkan tidak benar. Proses analisis dilakukan pada tabel tabel admin, di mana pada tabel ini terdapat kolom 'id_owner' yang memiliki data masukan berupa 0 (yang berarti baris tersebut adalah admin/owner) dan id dari admin dengan tipe owner yang menandakan bahwa baris tersebut sebagai operator dari owner yang id nya digunakan untuk mengisi kolom 'id_owner' dapat dilihat pada gambar 3 .

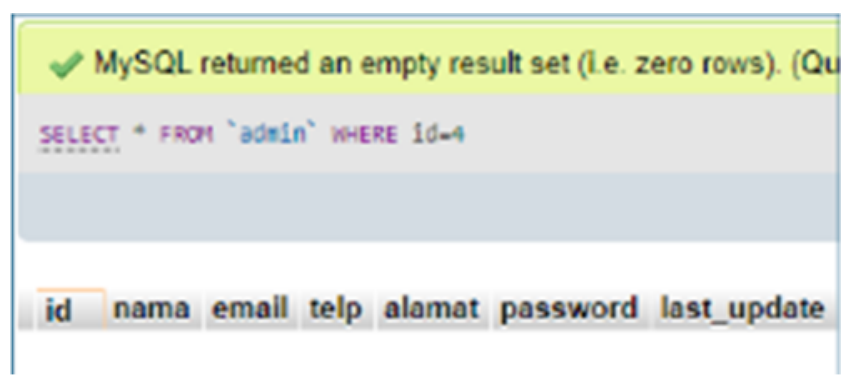

Gambar 3. Select tabel admin

Dari hasil query di atas menghasilkan keluaran kosong, atau data admin dengan id 4 tidak terdapat di tabel admin. Berikutnya peneliti mencoba memasukkan data admin baru dengan tipe operator dan kolom 'id_owner' diberikan nilai 4. Perintah query insert di bawah ini berhasil dijalankan walaupun id owner dengan nilai 4 tidak ada di tabel admin dapat dilihat pada gambar 4. 


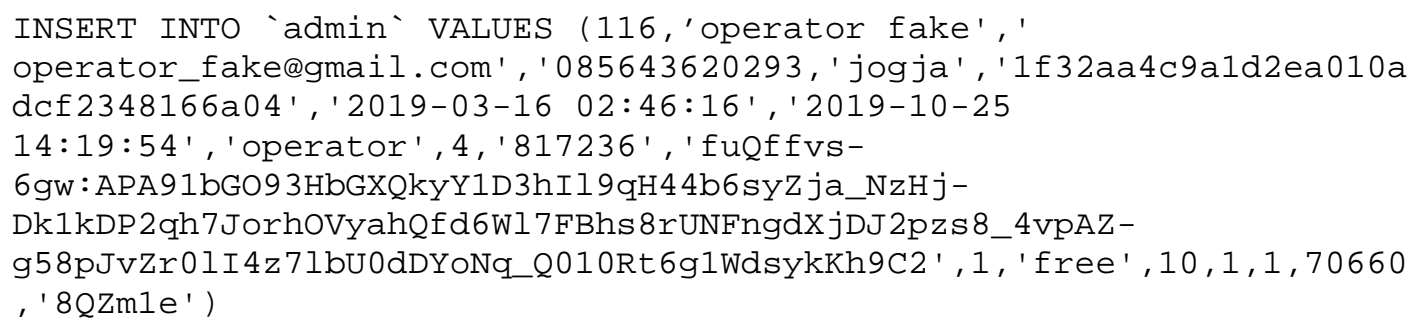

Gambar 4. Insert tabel admin

\subsection{Aspek Konsistensi}

Dalam aspek konsistensi ini lebih ditekankan terhadap masalah redudancy data yang tidak perlu, baik dalam tabel yang sama maupun tabel yang berbeda. Analisis terkait konsistensi data peneliti juga mengambil contoh dari tabel admin, di mana terdapat kolom 'type' yang dalam proses bisnisnya hanya boleh bernilai 'owner' dan 'operator' saja. peneliti mencoba melakukan update data dengan mengubah kolom 'type' menjadi bernilai 'operatos' dapat dilihat pada gambar 5.

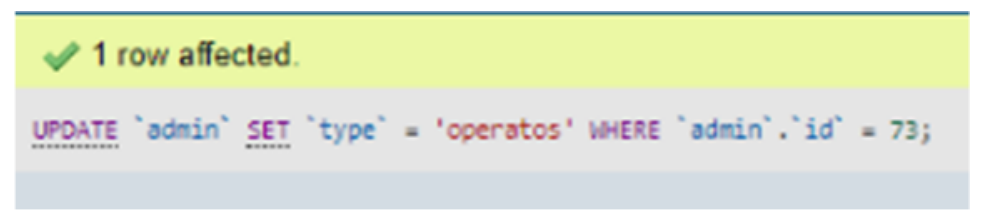

Gambar 5. Update tabel admin

Proses ubah data berhasil dilakukan, berikutnya peneliti mencoba membuktikan dengan melakukan perintah query select yang akan di group by 'type' dapat dilihat pada gambar 6 .

SELECT type, COUNT(*) as jumlah FROM 'admin' GROUP BY type

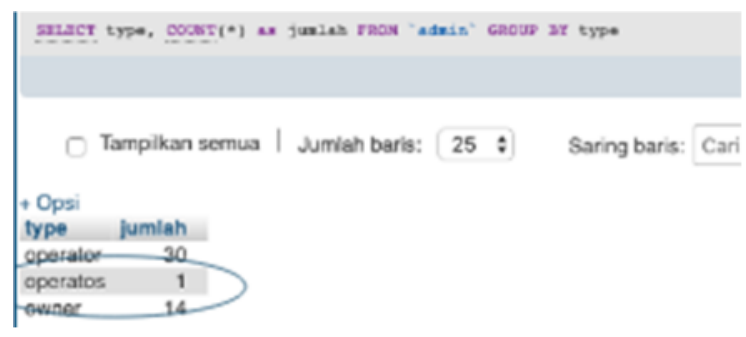

Gambar 6. Select group by kolom type

Dari hasil perintah query di atas menghasilkan tambahan jenis type baru yaitu 'operatos' yang membuat data tidak konsisten dan terlihat perulangan data/redudansi data .

\subsection{Aspek Relevansi}

Analisis kualitas skema dilihat dari aspek relevansi yaitu apakah skema basis data yang lama memuat skema yang relevan, baik dalam setiap tabel maupun relasi antar tabel. Untuk menguji aspek relevansi peneliti mengambil contoh pada tabel layanan dan harga layanan, di mana kedua tabel ini memiliki relasi satu layanan dapat memiliki lebih dari satu harga_layanan dapat dilihat pada gambar 7 .

SELECT * FROM 'layanan' WHERE id $=173$ 
Tampilkan kotak kueri

MySQL memberikan hasil kosong (atau nol baris). (Pencarian dilakukan dalam 0.0027 detik.)

SELECT * FROM 'layanan' WHERE id=173

id layanan kios_id satuan trash

Gambar 7. Select tabel layanan

Dari hasil query di atas menghasilkan keluaran kosong atau data layanan dengan id 173 tidak ada di tabel layanan. peneliti kemudian melakukan perintah query insert ke tabel harga_layanan dengan memberikan nilai 173 pada kolom 'layanan_id' dari proses tersebut query berhasil dijalankan seperti pada gambar 8 .

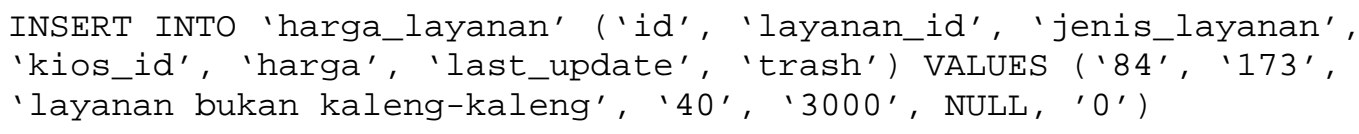

Gambar 8. Insert tabel harga_layanan

Selanjutnya peneliti melakukan perintah query join table 'layanan' dengan ‘harga_layanan' di mana yang 'id_layanan' adalah 173. Dari hasil query di bawah ini menghasilkan keluaran kosong, karena memang id 173 tidak terdapat di tabel 'layanan' meskipun id tersebut ada di tabel 'harga_layanan' dalam kolom 'id_layanan'. Dari hasil analisis ini dapat dibuktikan bahwa skema basis data lama belum menjamin aspek relevansi dalam hal ini antar tabel dapat dilihat pada gambar 9.

SELECT l.id, l.layanan, l.kios_id, l.satuan, hl.jenis_layanan, hl.kios_id, hl.harga from layanan 1, harga_layanan hl WHERE l.id= hl. layanan_id AND 1. id $=173$

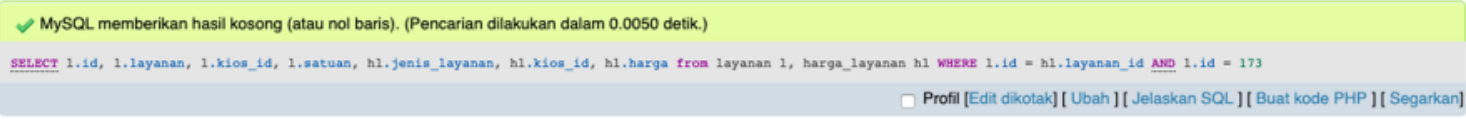

id layanan kios_id satuan jenis_layanan kios_id harga

Gambar 9. Join tabel layanan dan harga_layanan

Beberapa skenario perintah query di atas merupakan salah satu contoh langkah analisis kualitas skema basis data lama dilihat dari aspek kebenaran, konsistensi dan relevansi yang selanjutnya akan peneliti paparkan semua hasil tersebut dalam bentuk tabel. Berdasarkan hasil analisis skema basis data aplikasi LaundryPOS lama melalui perintah-perintah query dapat diketahui bahwa : 1) Setiap kolom yang berelasi tidak direlasikan menggunakan foreign key; 2) Terdapat duplikasi kolom yang sama pada kedua tabel yang saling berelasi; 3) Terdapat pemborosan kolom yang seharusnya tidak perlu diadakan kolom tersebut di dalam tabel. Berikut adalah beberapa kekurangan dalam skema basis data lama pada aplikasi LaundryPOS berdasarkan ketiga aspek di atas seperti pada tabel 1 di bawah ini. 
Tabel 1. Tabel kekurangan skema basis data lama

\begin{tabular}{|c|c|c|}
\hline Aspek & Tabel & Keterangan \\
\hline \multirow[t]{3}{*}{ Kebenaran } & admin & $\begin{array}{l}\text { Terdapat pada kolom 'id_owner' yang seharusnya berisi nilai } 0 \text { atau } \\
\text { id dari admin yang bertipe owner. Akan tetapi dapat diisi dengan id } \\
\text { admin yang tidak ada di tabel admin saat menambahkan data admin } \\
\text { sebagai operator. }\end{array}$ \\
\hline & $\begin{array}{l}\text { admin dan } \\
\text { paket_akun }\end{array}$ & $\begin{array}{l}\text { Kolom 'paket_akun_id' diisi dengan nama 'freeze' yang tidak ada } \\
\text { di tabel paket_akun, seharusnya adalah 'free' (id menggunakan tipe } \\
\text { data varchar). }\end{array}$ \\
\hline & admin & $\begin{array}{l}\text { Kolom email belum bersifat unique, dapat memasukkan nilai email } \\
\text { yang telah digunakan oleh akun lain saat menambahkan data baru. } \\
\text { Penambahan constraint unique dapat menyaring nilai masukan } \\
\text { email yang sama, sehingga tidak adanya email yang sama tiap } \\
\text { barisnya [10] }\end{array}$ \\
\hline \multirow[t]{3}{*}{ Konsistensi } & Admin & $\begin{array}{l}\text { Dapat menambahkan data pada kolom 'type' degan nilai selain } \\
\text { owner dan operator }\end{array}$ \\
\hline & $\begin{array}{l}\text { layanan, kios dan } \\
\text { harga_layanan }\end{array}$ & $\begin{array}{l}\text { Tabel layanan dan harga_layanan ini berelasi, dan di masing-masing } \\
\text { tabel terdapat kolom 'kios_id' yang berelasi dengan tabel kios. Data } \\
\text { harga_layanan yang berelasi dengan layanan dapat memiliki nilai } \\
\text { kios_id yang berbeda }\end{array}$ \\
\hline & $\begin{array}{l}\text { admin dan } \\
\text { paket_akun }\end{array}$ & $\begin{array}{l}\text { Kedua tabel ini berelasi, kolom 'jml_kios, jml_transaksi, } \\
\text { pesan_antar' terdapat di kedua tabel }\end{array}$ \\
\hline \multirow[t]{4}{*}{ Relevansi } & $\begin{array}{l}\text { transaksi dan } \\
\text { item_transaksi }\end{array}$ & $\begin{array}{l}\text { Dapat menambahkan item_transaksi dengan memasukkan } \\
\text { id_transaksi yang tidak ada di tabel transaksi, selain itu dapat } \\
\text { menghapus tabel transaksi yang id nya dipakai di tabel } \\
\text { item_transaksi }\end{array}$ \\
\hline & $\begin{array}{l}\text { kios, admin dan } \\
\text { operator_kios }\end{array}$ & $\begin{array}{l}\text { Dapat menambahkan data di operator_kios dengan masukan nilai } \\
\text { 'kios_id' yang tidak ada di tabel kios dan 'admin_id' yang tidak ada } \\
\text { di tabel admin }\end{array}$ \\
\hline & $\begin{array}{l}\text { layanan dan } \\
\text { harga_layanan }\end{array}$ & $\begin{array}{l}\text { Dapat menambahkan data harga_layanan dengan memasukkan } \\
\text { layanan_id yang tidak ada di tabel layanan }\end{array}$ \\
\hline & $\begin{array}{l}\text { transaksi, admin, } \\
\text { kios, dan } \\
\text { pelanggan }\end{array}$ & $\begin{array}{l}\text { Dapat menambahkan/mengubah data transaksi dengan memasukkan } \\
\text { nilai pada kolom 'admin_id', 'kios_id', 'pelanggan_id' yang } \\
\text { masing-masing tidak terdapat pada tabel admin, kios dan pelanggan }\end{array}$ \\
\hline
\end{tabular}

Dari hasil analisis yang peneliti lakukan, ada beberapa perlakuan terhadap skema basis data lama, antara lain : 1) Memecah tabel admin menjadi 2 tabel, yaitu tabel admin dan tabel operator dengan derajat kardinalitas 1 admin dapat memiliki lebih dari satu operator dan menghilangkan kolom 'type', 'id_owner', 'jml_transaksi', ‘jml_kios', dan 'pesan_antar'. Meskipun dengan melakukan langkah ini membutuhkan ruang penyimpanan tambahan, akan tetapi tujuannya untuk menyelesaikan masalah anomalitas [11]; 2) Menambah constraint relasi antar tabel yang berelasi dengan pilihan on update cascade dan on delete cascade pada setiap tabel yang memiliki relasi, sehingga dapat memfilter masukan data yang tidak terdapat pada tabel primer dan penghapusan data primer; 3) Menghapus kolom 'kios_id' yang terdapat pada tabel harga_layanan, karena antara layanan dan harga_layanan sudah berelasi; 4) Mengganti tipe data kolom id yang berupa varchar menjadi integer dengan attribut auto increment pada tabel paket_akun. Gambar 10 adalah hasil perbaikan rancangan skema basis data aplikasi LaundryPOS. 


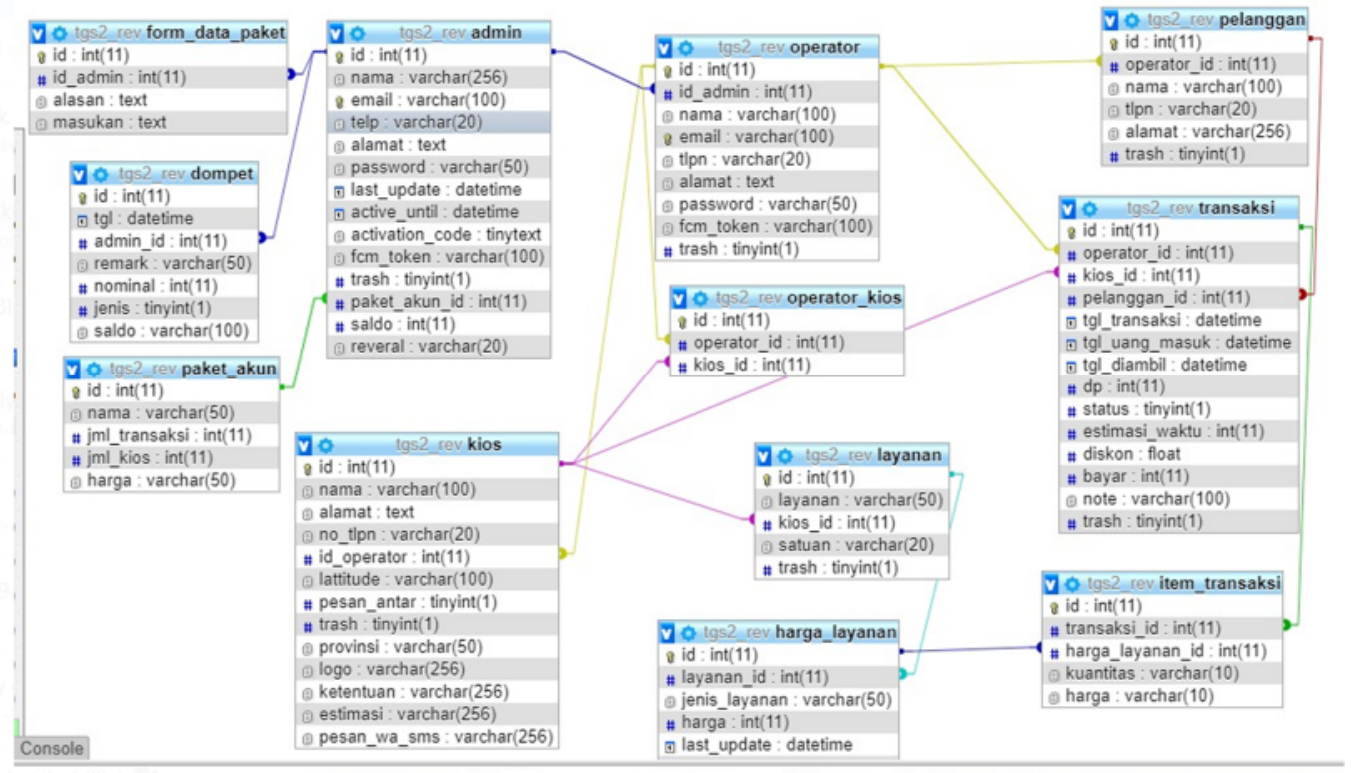

Gambar 10. Skema basis data baru

Setelah dilakukan proses analisis terhadap aspek kebenaran, konsistensi dan relevansi, akhirnya penulis menemukan rancangan schema basis data baru yang lebih efesien dan meminimalisasi redudansi sehingga dapat meningkatkan integritas data [12], untuk nantinya direkomendasikan kepada pihak pengembang aplikasi LaundryPOS.

\section{Kesimpulan}

Berdasarkan hasil penelitian terhadap aspek kualitas schema database diatas. Dapat disimpulkan bahwa schema database pada aplikasi LaundryPOS memiliki kualitas yang relatif kurang baik jika dinilai dari aspek kebenaran (correctness), konsistensi (consistency) dan relevansi (relevance). Kondisi kualitas schema database yang kurang baik seperti ini dapat menjadi potensi timbulnya berbagai permasalahan serius dikemudian hari. Oleh karena itu, perlu segera dilakukan upaya penyempurnaan untuk menghindari timbulnya permasalahan yang lebih kompleks dan semakin sulit ditangani.

\section{Saran}

Berdasarkan hasil penelitian terhadap aspek kualitas schema database diatas, peneliti mengajukan saran yang dapat diambil antara lain :

1. Evaluasi database dengan melakukan identifikasi kesalahan-kesalahan yang ada pada database dengan memperhatikan semua aspek (Kebenaran, konsistensi, Relevansi) terkait pemilihan Tipe data, Lebar data, Constrain dan kerelasian.

2. Membuat tools yang menyangkut tentang evaluasi schema database dan pengukuran kualitas data.

\section{Daftar pustaka}

[1] Silalahi M., Wahyudi D., 2018, Perbandingan Performansi Database MongoDB dan MySQL Dalam Aplikasi File Multimedia Berbasis Web, CBIS Journal, Vol. 6, No. 1, hal. 63-78, Universitas Putera Batam, Batam.

[2] Fabbri, A. J., Schwab, A. R., 1992, Practical Database Management, PWS-KENT, Boston 
[3] Toerey, J. T., 1999, Database Modelling \& Design, Third Edition, Academic Press, Cambrigde.

[4] Lawrence, R., 2014, Integration and Virtualization of Relational SQL and NoSQL Systems including MySQL and MongoDB, 2014 International Conference on Computational Science and Computational Intelligence, hal. 285-290, IEEE.

[5] Raharjo, S., Sutanta, E., \& Utami, E., 2007, Analisis Aspek-Aspek Kualitas Schema Database (Studi Kasus pada Database Akademik ISTA Yogyakarta), Seminar Nasional Teknologi, hal. D1 -D13, STIMIK Amikom, Yogyakarta.

[6] Prasetya, W. S., 2015, Perancangan Model Basis Data Relasional Dengan Metode Database Life Cycle. Seminar Nasional Informatika (SNIf), Vol. 1, No. 1, hal. 91-98, Universitas Potensi Utama, Medan.

[7] Lubis, J.H., 2017, Analisa Performansi Query Pada Database Smell. Jurnal Manajemen dan Informatika Pelita Nusantara, Vol. 21, No.1, hal. 42-49, STMIK Pelita Nusantara, Medan.

[8] Herden, O, 2001, Measuring Quality of Database Schemas by Reviewing-Concept, Criteria and Tool, $5^{\text {th }}$ International Workshop on Quantitative Approaches in Object-Oriented Software Engineering, hal. 59 - 70, Springer-Verlag, Berlin.

[9] Fikry, M., Malikussaleh, U., 2016, Rancangan Basis Data Kependudukan Berdasarkan Aspek-Aspek Kualitas Schema Database, Techsi, Vol. 8, No. 2, hal. 28-43.

[10] Wright, C. J., Kapfhammer, G. M., \& McMinn, P., 2014, The Impact of Equivalent, Redundant and Quasi Mutants on Database Schema Mutation Analysis, 2014 14th International Conference on Quality Software, hal. 57-66, IEEE.

[11] Teorey, T., Lightstone, S., Nadeau, T., \& Jagadish, H. V., 2006, Database Modeling and Design Fourth Edition, Morgan Kaufmann Publishers, San Francisco.

[12] Yunita, S., Sholeha, E. W., Hardita, V. C., dan Utami, E., 2018, Database Modelling for the Expertise of Special Needs Teachers, Journal of Physics Conference Series, Vol. 1140, No. 1, hal. 19. 